\title{
Prion disease risk perception in Canadian medical laboratories
}

\author{
Jane A Buxton MBBS MHSc FRCPC, Bonnie Henry MD MPH FRCPC, Aiza Waheed BSc, Alexis Crabtree BA MPH
}

\author{
JA Buxton, B Henry, A Waheed, A Crabtree. Prion disease risk \\ perception in Canadian medical laboratories. Can J Infect Dis \\ Med Microbiol 2012;23(2):e31-e35.
}

BACKGROUND: There are no national guidelines specific for handling prion-associated specimens in Canadian medical laboratories. Medical laboratory workers may perceive themselves at risk of prion transmission and, on occasion, decline to process such specimens.

OBJECTIVE: To examine the knowledge, attitudes and reported behaviours of medical laboratory workers in relation to prion disease to understand their risk perception and the need for national laboratory guidelines on prion infection control.

DESIGN: Survey development and cross-sectional web-based administration

METHODS: The survey was developed through key informant interviews and a modified Delphi process. Medical laboratory workers across Canada were invited by laboratory managers and national organizations to complete the web-based survey.

RESULTS: Twelve key informant interviews were performed. Consensus for questionnaire content was reached through two rounds of the Delphi process. Responses were received from 426 Canadian medical laboratory workers; $37 \%$ of medical laboratory staff reported processing prionassociated specimens. Different protocols for specimen processing were followed, and $18 \%$ believed they were at risk when processing these specimens. Less than one-third of those receiving specimens believed they were adequately trained. The mean $( \pm \mathrm{SD})$ knowledge score was $9.25 \pm 4.5 / 24$; individuals who had received training scored significantly higher than those who were untrained $(\mathrm{P}<0.01)$. Eighty-one per cent of respondents would be more comfortable processing specimens if national guidelines existed and were used in their laboratory.

CONCLUSION: There is a high perception of risk and few perceived benefits of processing prion-associated specimens. National guidelines for prion infection control in medical laboratories and adequate training would enable medical laboratory workers to process these specimens efficiently and confidently.

Key Words: Delphi technique; Laboratory personnel; Prions; Risk; Specimen handling

Drion diseases, such as Creutzfeldt-Jakob Disease (CJD), are characterized in humans by rapidly progressive dementia that is untreatable and invariably fatal. These neurodegenerative illnesses are attributed to an infectious protein agent known as a prion, which causes damage and death to nervous tissue and gives the tissue a sponge-like appearance.

Every year, between 30 and 40 cases of human prion disease are confirmed by the Canadian CJD Surveillance System (1). Diagnostic testing for prion diseases is handled by the National Microbiology Laboratory (NML) in Winnipeg (Manitoba). However, medical laboratories across Canada annually process hundreds of specimens from patients in whom prion disease is in the differential diagnoses and tests are requested to rule out other potentially treatable neurological illnesses.

Recommendations from the Public Health Agency of Canada outline precautions for managing the risks of prion transmission in clinical

\section{La perception du risque d'infection à prion dans les laboratoires médicaux canadiens}

HISTORIQUE : Il n'existe pas de lignes directrices nationales propres à
la manipulation d'échantillons associés aux infections à prion dans les
laboratoires médicaux canadiens. Les travailleurs de ces laboratoires
peuvent se percevoir comme vulnérables à la transmission d'une infection
à prion et parfois refuser de traiter ces échantillons. OBJECTIF : Examiner les connaissances, les attitudes et les comportements déclarés des travailleurs de laboratoire pour comprendre leur perception du risque et la nécessité de préparer des lignes directrices nationales de laboratoire sur le contrôle des infections à prion.

CONCEPTION : Élaboration de l'administration transversale d'un sondage par voie électronique

MÉTHODOLOGIE : Les chercheurs ont préparé le sondage par suite d'entrevues avec des informateurs clés et d'une méthode Delphi modifiée. Des directeurs de laboratoire et des organisations nationales ont invité les travailleurs de laboratoire du Canada à répondre au sondage par voie électronique.

RÉSULTATS : Les chercheurs ont effectué 12 entrevues auprès d'informateurs clés. Ils sont parvenus à un consensus quant au contenu du questionnaire après deux rondes de la méthode Delphi. Ils ont reçu la réponse de 426 travailleurs de laboratoire canadiens, dont $37 \%$ déclaraient traiter des échantillons liés à des infections à prion. Divers protocoles de traitement des échantillons étaient respectés, et $18 \%$ des travailleurs se sentaient vulnérables dans le cadre de ce traitement. Moins du tiers des travailleurs qui recevaient ces échantillons se sentaient bien formés pour le faire. L'indice de connaissance moyen s'élevait à 9,25/24 (ÉT士4,5). Les personnes qui avaient reçu une formation obtenaient un indice considérablement plus élevé que celles qui n'en avaient pas reçu $(\mathrm{P}<0,01)$. Quatre-vingt-un pour cent des répondants seraient plus à l'aise de traiter les échantillons s'il existait des lignes directrices nationales mises en œuvre dans leur laboratoire.

CONCLUSION : La perception du risque est élevée et celle des avantages du traitement des échantillons liés à des infections à prion est faible. Des lignes directrices nationales sur le contrôle des infections à prion dans les laboratoires médicaux et une formation convenable permettraient aux travailleurs de laboratoire de traiter ces échantillons avec efficacité et en toute confiance.

settings; however, detailed specific guidelines for medical laboratories do not currently exist (2). Although the risk of prion transmission during specimen processing is low and no cases of classical CJD have been attributed to laboratory exposure to date, laboratory workers may perceive themselves as being at risk from prion disease. Therefore, they may be reluctant to handle and process these specimens, resulting in testing delays (3-6).

Our project aimed to understand the prion disease risk perception of medical laboratory staff to assess whether there is a need for national guidelines on prion infection control that are specific to medical laboratories. The goal was to develop, administer and analyze the results of a web survey that examined the knowledge, attitudes and behaviour of medical laboratory staff in relation to processing specimens from patients with potential prion disease. This report summarizes the methodology of survey development, the results of our analysis and recommendations. 


\section{METHODS}

A web survey using key informant and focus group interviews, and a Delphi process, was developed. Ethics approval was obtained from the University of British Columbia's Behavioural Research Ethics Board (Vancouver, British Columbia). The survey development process is described in full elsewhere (7) and is therefore only briefly described here.

\section{Step 1: Qualitative interviews - information gathering}

Semistructured key informant interviews and one focus group were conducted to gain familiarity with the issues regarding prion safety in medical laboratories. A purposive sample of interviewees was selected from public health and hospital laboratories that receive prion-associated specimens in British Columbia and the NML. Interview questions explored topics such as current practice when handling potentially prion-infected tissues, perceived risks for laboratory staff and patients, and barriers to implementation of existing best practices (2). Interviews were held until data saturation was reached, defined as the point in which no new themes were identified in three interviews.

Interviews were audio-recorded and transcribed verbatim. Data were coded under the constructs of the Health Belief Model (HBM) (8) using NVivo software (QSR International Pty Ltd, Australia) by two independent coders. Coding was jointly refined and subthemes were identified by consensus.

\section{Step 2: Questionnaire refinement - Delphi process and pilot test} A draft questionnaire was developed using the qualitative HBM results from step 1, and the questions were ordered to reflect the work flow in a medical laboratory (eg, receiving a specimen, processing the specimen, decontamination of a workspace). The questionnaire included knowledge questions on prion transmission risk posed by different types of specimens, knowledge and use of personal protective measures and decontamination. This questionnaire was refined through a modified Delphi process with experts (including medical directors from hospitals, provincial and national laboratories and two epidemiologists with expertise in survey design).

The experts rated each question on a three-point scale (Yes - keep the question, Maybe - keep with some changes, No - remove the question) and were encouraged to justify their reasoning and suggest new wording or new questions. The moderator compiled the feedback and removed identifying information and circulated feedback to the group. The anonymous nature of the process ensured that questionnaire development was not influenced by one dominant point of view (9). This process was repeated until consensus was reached on all questions. A copy of the final survey is available from the authors on request.

The questionnaire was refined following online pilot testing by a convenience sample of four laboratory workers who assessed its readability, understandability and validity.

\section{Survey distribution and analysis}

Three national organizations were recruited to distribute the survey link to their members; Canadian Society for Medical Laboratory Science; Association of Medical Microbiology and Infectious Disease Canada; and Community and Hospital Infection Control Association - Canada. Medical laboratory managers and supervisors across Canada were also contacted to distribute the survey link to their staff and colleagues.

Responses with completed demographics and at least 20\% of the survey completed were included and analyzed using SPSS version 14 (IBM Corporation, USA). Frequencies for risk perception questions were calculated and cross-tabulations were developed for behaviour questions. P-values for categorical data were calculated using Pearson's $\chi^{2}$ test. A total score out of 24 was generated for the knowledge questions and $\mathrm{P}$-values for continuous data were calculated using ANOVA and independent samples $t$ tests. A level of significance of $\alpha=0.05$ was used.

\section{Key informant interview results}

\section{RESULTS}

A total of 12 persons participated in the interviews and focus groups. The following are examples of items from the transcriptions coded under the five constructs of the HBM.

1) Cues to action are triggers that lead an individual to take a protective measure, ie, a laboratory worker may follow their facility protocol or take extra precautions (eg, determining the likelihood of prion infection by contacting the requesting physician).

2) Perceived severity, ie, prion disease is untreatable and invariably fatal.

3) Perceived susceptibility, ie, receives conflicting information, there is 'no single set of rules' for prion infection control in medical laboratories.

4) Perceived barriers to following prion infection control protocols, ie, limited information relevant to medical laboratories and identification of CJD risk after processing the specimen.

5) Perceived benefits of timely processing a prion-associated specimen rather than sending to NML, ie, is a quick diagnosis worth the risk to staff? 'Is the patient still alive?'

Consensus was reached after two rounds of the Delphi process. The pilot test identified minor suggested changes, which were addressed before the survey was made available online.

\section{Survey demographics}

The survey was online for 24 days, during which time 426 usable responses were received; 44 responses were removed (25 duplicates and 19 with $<20 \%$ survey completion). Most respondents reported receiving the survey from their managers/supervisors. Responses were received from all the provinces and two territories and included different types of medical laboratories (eg, hospital, public health, microbiology, pathology). Table 1 summarizes the demographics of our survey respondents. Due to the method of survey distribution, it was not possible to calculate a response rate.

\section{Current practices in medical laboratories}

Receiving specimens from patients with potential prion disease occurs infrequently for most medical laboratories. Almost one-quarter (23\%) of respondents indicated that their facilities never receive these specimens and $37 \%$ were unsure. Of the $41 \%$ of respondents who indicated that their facilities received prion-associated specimens, $90 \%$ specified that they receive specimens less than once a month.

Over one-third (37\%) of respondents believed that prion-associated specimens were not appropriately labelled. Only one-quarter $(25 \%)$ of respondents reported that these specimens were labelled at their facilities. Other means of communicating potential prion risk in medical laboratories include requisition forms (42\%) and word of mouth, such as being told by co-workers, nurses, infection control officers and others (49\%).

Although laboratories use universal precautions (USA) or routine practices (Canada) to prevent prion transmission for all specimens (eg, cerebrospinal fluid testing), laboratory workers are concerned when they are made aware of prion risk after the specimen has been processed.

More then one-third (37\%) of respondents reported that their facility processes prion-associated specimens, $60 \%$ of these indicated that they followed a special protocol for prion infection control, while $25 \%$ followed usual practice. When laboratories do not process prionassociated specimens, these specimens may be sent to the NML (45\%), or another provincial, public health or hospital laboratory.

Of the respondents who work in facilities that do process prionassociated specimens, one-quarter indicated that their facilities take some extra steps before processing these specimens (eg, 17\% call the ordering physician to determine the likelihood of prion disease and process the specimen carefully if there is a high risk). Others may wait for further test results, such as the 14-3-3 protein determination test, and contact somebody in authority, (eg, the microbiologist on call, chief pathologist or medical laboratory director), before deciding 
TABLE 1

Demographics of survey respondents $(n=426)$

\begin{tabular}{|c|c|c|}
\hline & \multicolumn{2}{|c|}{ Respondents, } \\
\hline & $\mathrm{n}^{*}$ & $\%$ \\
\hline \multicolumn{3}{|l|}{ Sex } \\
\hline Female & 308 & 82.1 \\
\hline Male & 67 & 17.9 \\
\hline \multicolumn{3}{|l|}{ Occupation } \\
\hline Medical laboratory technologist & 276 & 64.8 \\
\hline Medical laboratory technician & 38 & 8.9 \\
\hline Medical laboratory assistant & 31 & 7.3 \\
\hline Manager & 25 & 5.9 \\
\hline Physician & 19 & 4.5 \\
\hline Administrative staff member & 5 & 1.2 \\
\hline Other & 32 & 7.5 \\
\hline \multicolumn{3}{|l|}{ Years worked in occupation } \\
\hline 5 years or less & 144 & 33.8 \\
\hline 6 years to 15 years & 105 & 24.7 \\
\hline More than 15 years & 174 & 40.8 \\
\hline \multicolumn{3}{|l|}{ Laboratory type $^{\dagger}$} \\
\hline Microbiology & 117 & 27.5 \\
\hline Hematology & 119 & 27.9 \\
\hline Chemistry & 86 & 20.2 \\
\hline Biochemistry & 39 & 9.2 \\
\hline Pathology & 59 & 13.8 \\
\hline Virology & 28 & 6.6 \\
\hline Provincial & 18 & 4.2 \\
\hline Community & 39 & 9.2 \\
\hline Private & 22 & 5.2 \\
\hline Rural & 17 & 4.0 \\
\hline Hospital & 236 & 55.4 \\
\hline Public health laboratory & 32 & 7.5 \\
\hline Other & 69 & 16.2 \\
\hline \multicolumn{3}{|l|}{ Province } \\
\hline British Columbia & 154 & 36.3 \\
\hline Alberta & 76 & 17.9 \\
\hline Saskatchewan & 27 & 6.4 \\
\hline Manitoba & 10 & 2.4 \\
\hline Ontario & 106 & 25.0 \\
\hline Quebec & 5 & 1.2 \\
\hline New Brunswick & 18 & 4.2 \\
\hline Nova Scotia & 20 & 4.7 \\
\hline Prince Edward Island & 4 & 0.9 \\
\hline Newfoundland and Labrador & 2 & 0.5 \\
\hline Northwest Territories & 1 & 0.2 \\
\hline Nunavut & 1 & 0.2 \\
\hline
\end{tabular}

*Some responses are missing, as a result each category does not add up to 426; ${ }^{\dagger}$ Not mutually exclusive

whether to proceed with processing. Some individuals reported processing depended on the type of specimen received and that extra precautions were taken if the specimen was high risk (eg, brain tissue). Individuals also indicated that specimens were often processed before potential prion disease risk was identified.

Table 2 summarizes what percentage of laboratory protocols from facilities that process prion-associated specimens outline current best practices.

Attitudes and behaviours

The majority (90\%) of workers from laboratories that process prionassociated specimens stated that they have never refrained from processing these specimens. The $10 \%$ that ever refrained were more likely to take additional precautions and to be concerned about contracting
TABLE 2

Prion infection control protocols reported by respondents working in laboratories that process prion-associated specimen $(n=155)$

\begin{tabular}{lc}
\hline & $\begin{array}{c}\text { Per cent } \\
\text { reporting } \\
\text { precaution } \\
\text { outlined in } \\
\text { protocols }\end{array}$ \\
Precaution (best practices) & 39 \\
\hline Double gloving & 42 \\
Safety glasses & 50 \\
Absorbent pads under specimens & 50 \\
Labelling specimens for proper disposal & 53 \\
Wearing face shield when there is a risk of splashes & 54 \\
Using disposable water-resistant gowns & 54 \\
Taking specific measures to avoid spills & 56 \\
Taking specific measures to avoid aerosol formation & 57 \\
Taking specific measures to avoid injuries with sharps & 59 \\
Using disposable instruments/incineration after procedure & 60 \\
Labelling specimen as potential prion risk before sending & \\
to other facilities & 69 \\
Opening specimen in biosafety cabinet &
\end{tabular}

Information adapted from reference 2

prion disease when processing prion specimens. Seventy-two per cent reported they understand the science and reasoning behind their facilities' protocols. However, $14 \%$ believed that the protocol does not protect them from prion transmission, $18 \%$ of individuals believed that they were at risk of prion transmission when processing prionassociated specimens and $23 \%$ have used precautions above those mentioned in their protocols when processing such specimens in the past year. One-half of respondents reported experiencing anxiety when processing prion-associated specimens.

Some respondents who directly handle prion-associated specimens reported unprotected exposure to prion-associated specimens during processing over the past year. For example, $8.5 \%$ of individuals reported skin contact with specimen fluid, $2.5 \%$ had cut their skin during processing and $2.4 \%$ had inhaled aerosolized fluids. One-half of these individuals did not report the incident to their supervisors or someone in authority. The reasons for not reporting included believing they were not at risk of illness (25\%), worrying about looking unprofessional $(12.5 \%)$, not knowing who to tell about the incident (12.5\%), having to wait in an emergency room for hours and feeling alienated (12.5\%), washing the area immediately and handling the issue on their own (25\%) and not having a protocol at their facility that requires reporting when fluid comes in contact with skin (12.5\%).

Sixteen per cent of respondents did not feel comfortable approaching their supervisors to ask questions if they were unsure about how to handle specimens from patients with potential prion disease.

Only $44 \%$ said that their facilities were adequately equipped to process specimens from patients with potential prion disease. Of the individuals who directly work with prion-associated specimens, only $33 \%$ reported that they were adequately trained to handle such specimens.

Table 3 shows the behaviours of laboratory workers who have direct contact with specimens from patients with potential prion diseases according to their level of training. There were no significant differences in most of the best practices followed by individuals with differing levels of training. However, workers who felt they were adequately trained in prion infection control were more likely to label specimens as prion disease risks than individuals who were unsure about their training and those that felt they were not trained adequately. Medical laboratory technologists as a group were significantly more likely to double glove, but no difference was identified in other reported precautions taken. 


\section{TABLE 3}

Cross-tabulation of behaviour according to level of training for individuals who directly work with prionassociated specimens $(n=83)$

\begin{tabular}{|c|c|c|c|c|}
\hline \multirow{2}{*}{$\begin{array}{l}\text { I take the following } \\
\text { precautions when } \\
\text { handling specimens from } \\
\text { patients with potential } \\
\text { prion disease }\end{array}$} & \multicolumn{4}{|c|}{$\begin{array}{c}\text { I have been adequately trained in handling } \\
\text { specimens from patients with potential } \\
\text { prion disease }\end{array}$} \\
\hline & Agree & $\begin{array}{l}\text { Neither } \\
\text { agree nor } \\
\text { disagree }\end{array}$ & $\begin{array}{c}\text { Disagreel } \\
\text { don't know }\end{array}$ & $\mathbf{P}$ \\
\hline Double glove & & & & 0.716 \\
\hline Never/seldom & $12(44)$ & $6(55)$ & $19(54)$ & \\
\hline Always/sometimes & $15(56)$ & $5(45)$ & $16(46)$ & \\
\hline Wear safety glasses & & & & 0.356 \\
\hline Never/seldom & $14(56)$ & $4(33)$ & $18(56)$ & \\
\hline Always/sometimes & $11(44)$ & $8(67)$ & $14(44)$ & \\
\hline $\begin{array}{l}\text { Use face shield when } \\
\text { there is risk of splashes }\end{array}$ & & & & 0.990 \\
\hline Never/seldom & $10(37)$ & $4(36)$ & $12(35)$ & \\
\hline Always/sometimes & $17(63)$ & $7(64)$ & $22(65)$ & \\
\hline $\begin{array}{l}\text { Open specimen in } \\
\text { biosafety cabinet }\end{array}$ & & & & 0.290 \\
\hline Never/seldom & $4(15)$ & $3(25)$ & $11(33)$ & \\
\hline Always/sometimes & $22(85)$ & $9(75)$ & $22(67)$ & \\
\hline $\begin{array}{l}\text { Wear a disposable water- } \\
\text { resistant gown }\end{array}$ & & & & 0.092 \\
\hline Never/seldom & $6(22)$ & $4(31)$ & $17(49)$ & \\
\hline Always/sometimes & $21(78)$ & $9(69)$ & $18(51)$ & \\
\hline $\begin{array}{l}\text { Use disposable } \\
\text { instruments and } \\
\text { incinerate after } \\
\text { procedure }\end{array}$ & & & & 0.785 \\
\hline Never/seldom & $7(27)$ & $4(31)$ & $11(35)$ & \\
\hline Always/sometimes & $19(73)$ & $9(69)$ & $20(65)$ & \\
\hline $\begin{array}{l}\text { Use absorbent pads } \\
\text { beneath specimens that } \\
\text { would usually touch work } \\
\text { surfaces }\end{array}$ & & & & 0.313 \\
\hline Never/seldom & $7(27)$ & $3(23)$ & $14(42)$ & \\
\hline Always/sometimes & $19(73)$ & $10(77)$ & $19(58)$ & \\
\hline $\begin{array}{l}\text { Label specimen as a } \\
\text { potential prion disease } \\
\text { risk when sending it for } \\
\text { disposal }\end{array}$ & & & & 0.028 \\
\hline Never/seldom & $7(26)$ & $2(18)$ & $16(55)$ & \\
\hline Always/sometimes & $20(74)$ & $9(82)$ & $13(45)$ & \\
\hline $\begin{array}{l}\text { Label specimen as a } \\
\text { potential prion disease } \\
\text { risk when sending it for } \\
\text { further testing }\end{array}$ & & & & 0.010 \\
\hline Never/seldom & $3(12)$ & $2(17)$ & $15(45)$ & \\
\hline Always/sometimes & $23(88)$ & $10(83)$ & $18(55)$ & \\
\hline $\begin{array}{l}\text { Incineration of instruments } \\
\text { used on tissues that may } \\
\text { contain prions }\end{array}$ & & & & 0.861 \\
\hline Never/seldom & $9(41)$ & $4(36)$ & $11(46)$ & \\
\hline Always/sometimes & $13(59)$ & $7(64)$ & $13(54)$ & \\
\hline
\end{tabular}

Data presented as $n$ (\%) unless otherwise indicated. Data were analyzed using $\chi^{2}$ tests. Percentages are calculated from the totals in every column

The majority of people from laboratories that process prionassociated specimens $(57 \%)$ indicated a moderate to large amount of inconvenience associated with receiving prion-associated specimens. Furthermore, $81 \%$ of respondents indicated that they would be more
TABLE 4

Knowledge scores for laboratory workers who directly work with prion-associated specimens $(n=83)$

\begin{tabular}{lcc}
\hline & Mean score \pm SD & $\mathbf{P}$ \\
\hline Experience, years working in current position & & 0.954 \\
5 years or less $(\mathrm{n}=21)$ & $8.19 \pm 4.16$ & \\
6-15 years $(\mathrm{n}=23)$ & $8.61 \pm 5.36$ & \\
>15 years $(\mathrm{n}=36)$ & $8.53 \pm 4.88$ & \\
Training (I have been adequately trained to & & $<0.01$ \\
handle specimens from patients with potential & & \\
prion disease) & & \\
$\quad$ Agree ( $\mathrm{n}=27$ ) & $10.93 \pm 2.95$ & \\
$\quad$ Neither agree nor disagree ( $\mathrm{n}=13)$ & $10.31 \pm 5.11$ & \\
$\quad$ Disagree ( $\mathrm{n}=41$ ) & $6.27 \pm 4.66$ & \\
Occupation & & \\
Medical laboratory technologists $(\mathrm{n}=50)$ & $8.22 \pm 4.41$ & \\
Medical laboratory technicians/assistants ( $\mathrm{n}=23)$ & $7.78 \pm 5.48$ & \\
Physicians/managers/administration/nurses/ & $12.00 \pm 3.55$ & \\
$\quad$ infection control/clinical staff ( $\mathrm{n}=8$ ) & & \\
\hline
\end{tabular}

Respondents who answered "Don't know" were scored as 0

comfortable processing these specimens if a detailed national guideline on prion infection control that was specific to medical laboratories existed.

Knowledge questions

The mean $( \pm \mathrm{SD})$ correct score for the knowledge section was $9.25 \pm 4.5 / 24$. Table 4 summarizes the effect of experience, level of training and occupation on the knowledge scores of laboratory workers who work directly with prion-associated specimens. Knowledge score was not associated with number of years working in an occupation, but respondents who believed they had been adequately trained to handle prion-associated specimens scored significantly higher.

Although there were no significant differences in knowledge scores with respect to the occupation of the workers who directly handle prion-associated specimens $(n=83)$, physician and managers scored significantly higher $(12.05 \pm 1.05)$ than laboratory technologists $(8.55 \pm 0.61)$ and laboratory technicians/assistants $(8.72 \pm 1.29)$ for the entire sample $(\mathrm{P}<0.01, \mathrm{n}=426)$.

\section{DISCUSSION}

The results of our survey confirm that medical laboratory workers have concerns when handling specimens from patients with potential prion disease and report few perceived benefits to processing these specimens in a timely manner. Furthermore, the prion disease potential was often identified after the specimen had been processed; this may be because specimens are sent to the laboratory before the patient is seen by the neurologist and prion disease enters the differential diagnosis or due to improper labelling of specimens.

Currently, medical laboratories follow differing practices for processing prion-associated specimens and the vast majority of respondents indicated they would be more comfortable handling specimens if consistent national guidelines existed. It is concerning that only onehalf of respondents who worked in laboratories reported that their protocols include standard precautions. The lack of exposure reporting also suggests that individuals may have a poor understanding of standard precautions.

More than one-half of our respondents who directly handle prionassociated specimens reported receiving no specific training for doing so. Individuals who reported adequate training in prion infection control were significantly more likely to label specimens appropriately before sending them for incineration or further processing and also attained higher knowledge scores. Taking appropriate personal protective measures were not related to training; however, we may have been unable to detect a difference due to the small sample size. It has 
been shown that training programs can impact knowledge and behaviour, and enable workers to take appropriate actions (10); therefore, we suggest there is a need for training regarding prion infection control for medical laboratory staff.

Overall, knowledge scores were low and were not associated with years of experience. Physicians, including medical microbiologists and pathologists, and managers who supervise medical laboratories scored significantly higher on the knowledge questions than laboratory technologists, technicians and assistants, who are more likely to come into direct contact with prion-associated specimens. This finding suggests that supervisors are knowledgeable about prion disease; however, the information may not be made readily available to bench staff. Furthermore, one-half of the staff who had skin or mucous membrane exposures to potentially infected specimens did not report the exposure to their supervisors, and some staff were reluctant to approach their supervisors if they were unsure how to handle the specimens.

\section{CONCLUSIONS}

Our study identified the need for prion disease information to be made readily available to medical laboratory workers, particularly through

\section{REFERENCES}

1. Public Health Agency of Canada (PHAC) Creutzfeldt-Jakob Disease Surveillance System statistics. PHAC; 2009. <www.phacaspc.gc.ca/hcai-iamss/cjd-mcj/cjdss-ssmcj/stats-eng.php> (Accessed November 16, 2009).

2. Health Canada. Infection Control Guidelines: Classic CreutzfeldtJakob disease in Canada. Can Commun Dis Rep 2002;28:S5.

3. Fichet G, Comoy E, Dehen C, et al. Investigations of a prion infectivity assay to evaluate methods of decontamination. J Microbiol Methods 2007;70:511-8.

4. Louie JK, Gavali SS, Belay ED, et al. Barriers to Creutzfeldt-Jakob disease autopsies, California. Emerging Infect Dis 2004;10:1677-80.

5. Lillquist PP, Thomas N, Belay ED, Schonberger LB, Morse D. Barriers to autopsy: Creutzfeldt-Jakob disease in New York state. Neuroepidemiology 2006;26:207-11.

6. Tanwani LK, Furman CD, Ritchie CS. Diagnostic challenges in Creutzfeldt-Jakob disease: Case report. South Med J 2003;96:832-5. training. Additionally, we suggest the development of national guidelines for prion infection control in medical laboratories that address inconsistencies among laboratories and provide medical laboratory workers with the tools to process these specimens efficiently and with confidence.

ACKNOWLEDGEMENTS: The authors thank Drs Martin Petric and Patrick Doyle, who participated in the Delphi process; the numerous laboratory managers, CSMLS, AMMI Canada and CHICA Canada, who distributed the survey link; the medical laboratory workers who participated in the survey; Rebecca Haber, who assisted in interview coding; Dr Eleni Galanis, who translated the survey introduction into French; and Andrew $\mathrm{Tu}$, who performed the statistical analysis.

FINANCIAL SUPPORT: Funding for this study is provided through a High-Impact Grant from PrioNet Canada, a Canadian Network of Centres of Excellence (NCE) for prion disease research.

POTENTIAL CONFLICTS OF INTEREST: All authors report no conflicts of interest relevant to this article.

7. Buxton JA, Henry B, Crabtree A, Waheed A, Coulthart MB. Using qualitative methods to investigate risk perception of Canadian medical laboratory workers in relation to current prion disease infection control policies. J Toxicol Environ Health 2011;74:241-7.

8. Garcia K, Mann T. From 'I Wish' to 'I Will': Social-cognitive predictors of behavioral intentions. J Health Psychol 2003;8:347-60.

9. Dalkey Norman C. The Delphi Method: An Experimental Study of Group Opinion. Santa Monica: RAND Corporation, 1969.

10. Wang H, Fennie K, He G, Burgess J, Williams AB. A training programme for prevention of occupational exposure to bloodborne pathogens: Impact on knowledge, behavior and incidence of needle stick injuries among student nurses in Changsha, People's Republic of China. J Adv Nurs 2003;41:187-94. 


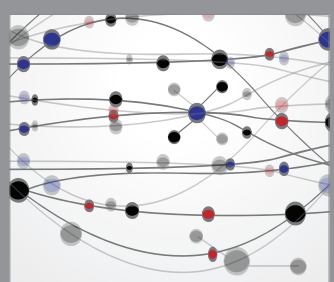

The Scientific World Journal
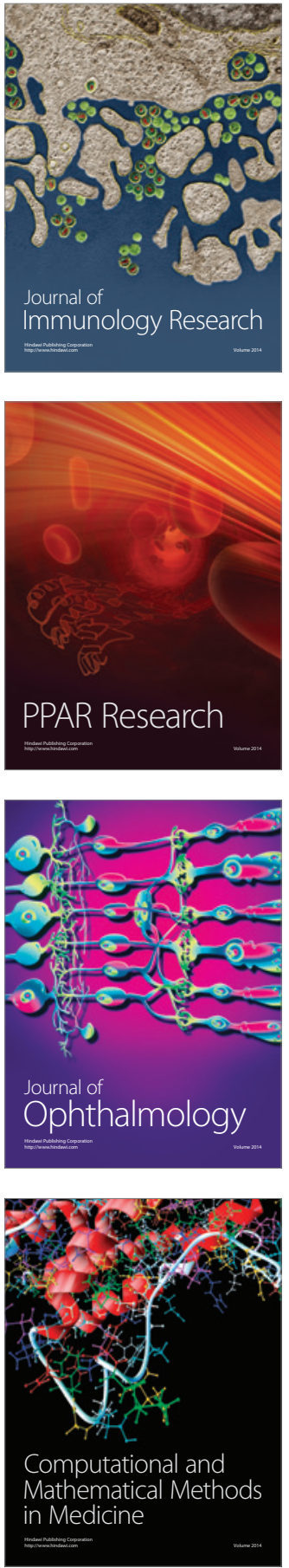

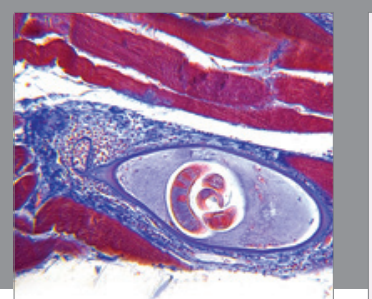

Gastroenterology Research and Practice

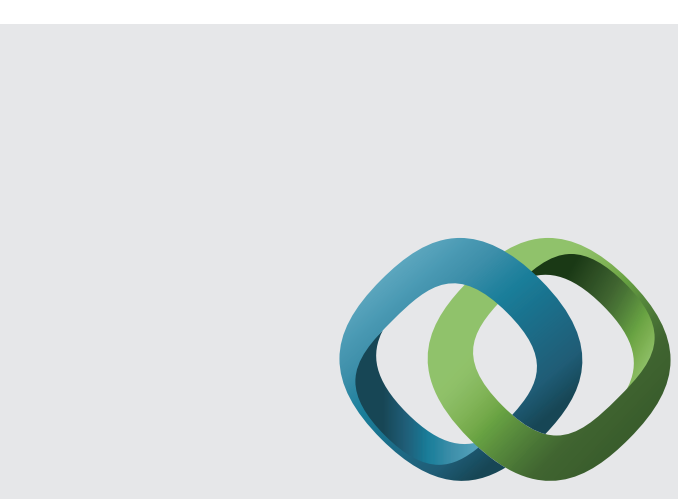

\section{Hindawi}

Submit your manuscripts at

http://www.hindawi.com
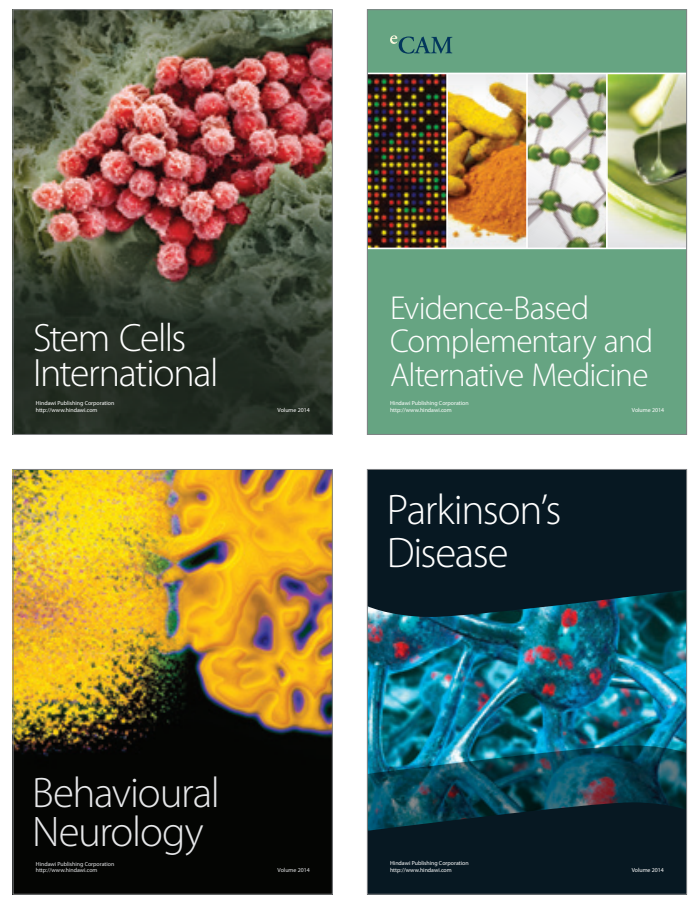
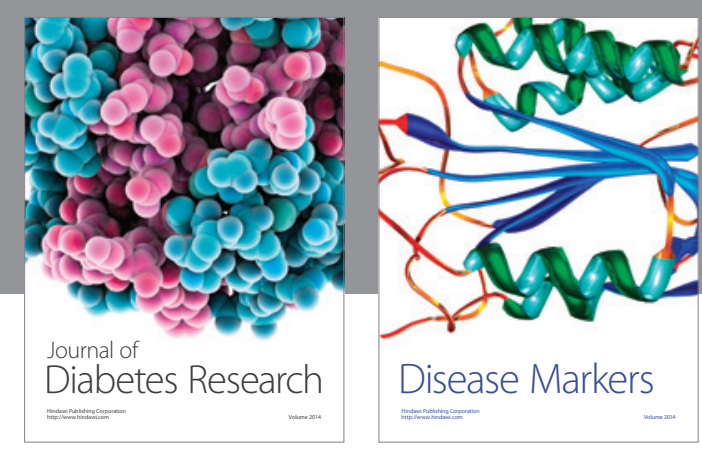

Disease Markers
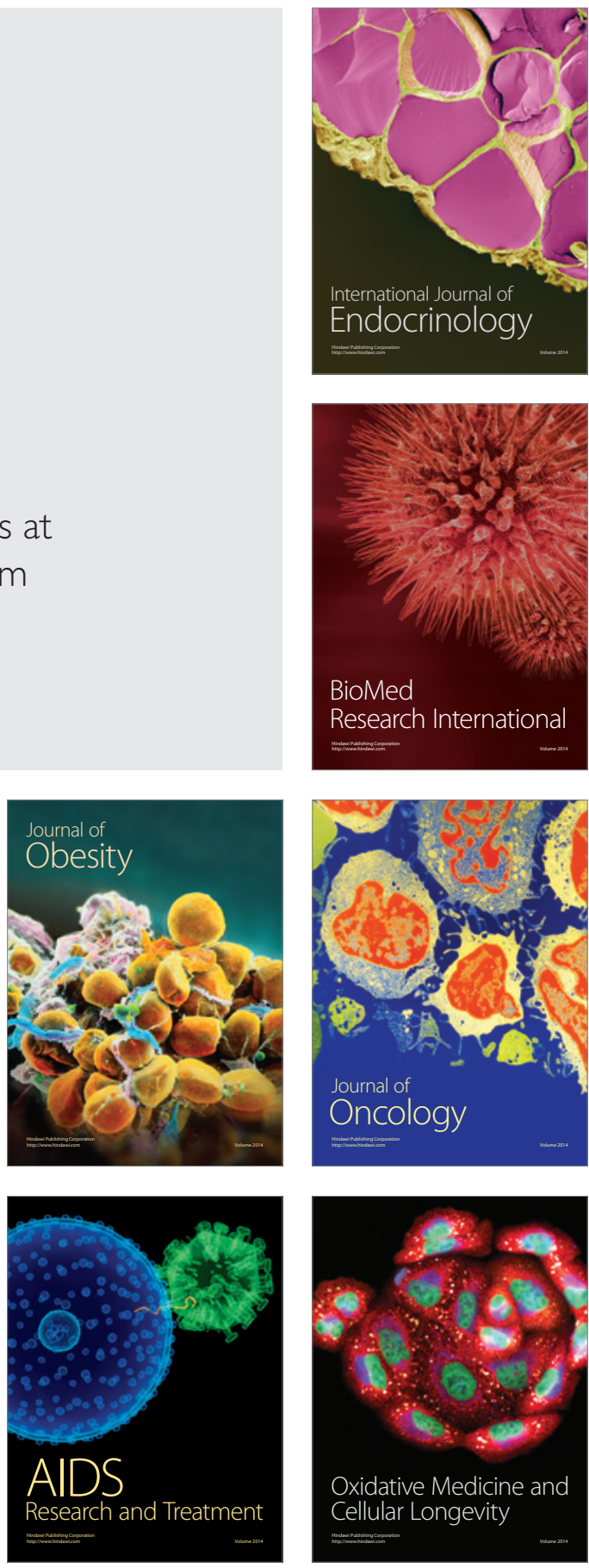